\title{
Alteração nas frações das proteínas miofibrilares e maciez do músculo Longissimus de bovinos no período post mortem
}

\author{
Changes in the fractions of myofibrillar proteins and tenderness of "Longissimus" \\ muscle of cattle in the "post mortem" period
}

\section{SANTOS, Gilmara Bruschi ${ }^{1}$; RAMOS, Paulo Roberto Rodrigues ${ }^{2}$; SPIM, Jeison Solano}

\author{
${ }^{1}$ Faculdades Gammon, Departamento de zootecnia, Paraguaçu Paulista, São Paulo / Faculdade de \\ Tecnologia , Ourinhos, São Paulo, Brasil. \\ ${ }^{2}$ Universidade Estadual Paulista, Departamento de Biofísica, Botucatu, São Paulo, Brasil. \\ ${ }^{3}$ Médico Veterinário, Autônomo, Brasília, Distrito Federal, Brasil. \\ *Endereço para correspondência: gilbruschi@yahoo.com.br
}

\section{RESUMO}

Objetivou-se com o estudo identificar por eletroforese as mudanças nas frações das proteínas musculares durante período postmortem de bovinos de diferentes grupos genéticos e analisar a maciez da carne em amostras resfriadas por 24 horas (não maturadas) e maturadas por 7 dias. Foram utilizadas amostras do musculo Longissimus de quarenta e oito bovinos pertencentes a 4 grupos genéticos: 12 Nelore; 12 cruzados $1 / 2$ Nelore $1 / 2$ Aberdeen-Angus $\mathrm{X}$ Brahman; 12 Brangus; 12 cruzados $1 / 2$ nelore $1 / 2$ Aberdeen-Angus x Pardo, submetidos ao modelo biológico superprecoce. De cada uma delas foram retiradas duas fatias, uma não foi maturada e a outra maturada por 7 dias, a $2^{\circ} \mathrm{C}$. Na análise da força de cisalhamento, tanto as amostras não maturadas, quanto as submetidas a 7 dias de maturação não diferiram quanto à maciez da carne, mas todas apresentaram maciez aceitável, o que pode ser explicado pela baixa idade dos animais no momento do abate, o que foi proporcionado pelo sistema de engorda a que estes animais foram submetidos. $\mathrm{Na}$ análise das bandas de proteínas da carne, medida pela eletroforese, notou-se degradação da cadeia pesada da miosina e da Troponina $-\mathrm{T}$ e $\mathrm{O}$ aparecimento do fragmento de $30 \mathrm{kDa}$ para todos os grupos genéticos após o período de 7 dias de maturação.Todos os grupos genéticos apresentaram boa maciez da carne, independentemente do tempo de maturação.

Palavras-chave: bovinos superprecoces, eletroforese SDS-Page, força de cisalhamento, grupo genético, proteólise miofibrilar

\section{SUMMARY}

The objective of this study was to identify by electrophoresis the changes in the fractions of muscle proteins during the post mortem period of different genetic groups and analyse the tenderness of meat samples refrigerated for 24 hours (not aged) and aged for 7 days. Were used forty-eight samples of Longissimus muscle from bovines of 4 genetic groups: 12 Nelore; 12 crossed $1 / 2$ Aberdeen-Angus $1 / 2$ Nelore $\mathrm{X}$ Brahman; 12 Brangus; 12 crossed 1/2 AberdeenAngus $1 / 2$ Nelore $x$ Pardo submitted to superprecoce biological model. From each sample two slices was retired, one of them was not aged and the other was aged for 7 days at $2^{\circ} \mathrm{C}$. In the analysis of shear force, both the nonaged samples, as those subjected to seven days of maturation did not differ on meat tenderness, but all of them showed acceptable tenderness, which can be explained by the low age at slaughter, which was provided by the fattening system that these animals were submitted. In the eletrophoretic analysis of bands of protein was noted degradation of myosin heavy chain and Troponin- $\mathrm{T}$ and the appearance of the $30 \mathrm{kDa}$ fragment for all genetic groups after the 7 days period of aging. All the genetic groups showed good meat tenderness, regardless the ageing time.

Keywords: superprecoce cattle, SDS-Page electrophoresis, shear force, genetic group, myofibrillar proteolysis 


\section{INTRODUÇÃOO}

A maciez é considerada como o atributo mais importante pelo consumidor no retorno à compra de um corte (HUFF LONERGAN et al., 2010). Porém, um programa que possa assegurar carne com maciez garantida não é de tão simples aplicação (KOOHMARAIE et al., 2006).

O grupo genético do animal tem efeito na maciez da carne, sendo a de origem indiana (Bos indicus)considerada menos macia em relação àquela de origem europeia (Bos taurus). Porém, em alguns estudos verifica-se que a maciez pode ser melhorada por meio da maturação até mesmo para as raças não especializadas (MÓNSON et al., 2004; SAÑUDO et al., 2004).

A maturação da carne, que ocorre postmortem, é resultado de uma série de eventos bioquímicos, que envolve principalmente o sistema enzimático calpaína-calpastatina, cuja finalidade é degradar-inibir a degradação da estrutura miofibrilar (HUFF LONERGAN et al., 2010). A maior parte da maciez no músculo Longissimus pode ser explicada pelas mudanças nas proteínas miofibrilares, no período post-mortem (SAWDY, 2004; MARINO, 2013).

A eletroforese na presença de dodecil sulfato de sódio (SDS-PAGE) vendo sendo empregada para a caracterização das mudanças nos padrões das proteínas associadas à maciez da carne (CLAYES et al., 1995; PIGHIN, 2012; MARINO, 2013). Esta técnica tem por finalidade evidenciar os padrões polimórficos das proteínas, dissociando suas cadeias polipeptídicas em cadeias simples e com cargas negativas, sendo possível determinar $\mathrm{o}$ peso molecular dos componentes proteicos do músculo, além de ser amplamente utilizada para análise qualitativa de proteínas e suas subunidades (CLAYES et al., 1995).

Muitas proteínas miofibrilares apresentam modificações em seu conteúdo, levando ao aparecimento de polipeptídeos de menor peso molecular na eletroforese (SDS-PAGE) (PIGHIN, 2012). Entre os produtos originados da degradação das dessas proteínas, o aparecimento da banda de $30 \mathrm{kDa}$ é predominante e tem sido reportada por muitos pesquisadores como indicador da degradação miofibrilar $\mathrm{e}$, consequentemente, da maior maciez da carne (MARINO, 2013).

Diante do exposto, este trabalho teve como objetivo identificar mudanças no padrão eletroforético das proteínas miofibrilares durante a maturação do músculo Longissimus de bovinos de quatro diferentes grupos genéticos, submetidos ao modelo biológico superprecoce e verificar as diferenças na força de cisalhamento da carne destes animais.

\section{MATERIAL E MÉTODOS}

Os animais utilizados neste trabalho pertenciam ao Confinamento Experimental do Departamento de Melhoramento e Nutrição Animal da Faculdade de Medicina Veterinária e Zootecnia (FMVZ) - UNESP Botucatu, SP.

Quarenta e oito bovinos pertencentes a 4 grupos genéticos: 12 Nelore; 12 cruzados 1/2 Nelore 1/2 Aberdeen-Angus $\mathrm{x}$ Brahman; 12 Brangus e 12 cruzados $1 / 2$ nelore $1 / 2$ Aberdeen-Angus x Pardo foram desmamados aos sete meses de idade em sistema de comedouro privativo (creep feeding) e confinados até atingirem o peso de abate $\mathrm{e}$ terminação de carcaça estabelecidos pelo modelo biológico superprecoce, com aproximadamente $450 \mathrm{~kg}$. 
Estes animais foram abatidos no frigorífico Marfrig, localizado no município de Promissão, estado de São Paulo, sob Serviço de Inspeção Federal (SIF 2543). Antes do abate os animais foram pesados e receberam apenas dieta hídrica por 16 horas. O procedimento de abate seguiu as normas previstas pelo Serviço de Inspeção Federal de acordo com a Instrução Normativa $\mathrm{n}^{0} 3$, de 17 de janeiro de 2000 (BRASIL, 2000).

As carcaças foram divididas ao meio, pesadas individualmente e devidamente identificadas. Decorridas 24 horas de resfriamento em temperatura de $2^{\circ} \mathrm{C}$, estas carcaças foram retiradas, realizando as coletas de amostras para análises. Doze amostras de cada grupo genético, utilizadas no presente trabalho, foram retiradas da porção ente a $11^{\mathrm{a}}$ e $13^{\mathrm{a}}$ costelas do músculo Longissimus de cada animal do experimento. Cada amostra obtida apresentava aproximadamente $2,5 \mathrm{~cm}$ de espessura. Cada amostra foi dividida ao meio, uma foi embalada a vácuo e submetida ao processo de maturação a aproximadamente $2^{\circ} \mathrm{C}$ por sete dias para posterior análise da força de cisalhamento e a outra foi imediatamente submetida ao procedimento, como detalhado abaixo.

As amostras foram assadas em forno elétrico até atingirem temperatura interna de $71^{\circ} \mathrm{C}$. Após este processo, as amostras permaneceram resfriadas por 24 horas quando então, foi realizada a determinação da força de cisalhamento (WHEELER et al., 1997). Foram retirados oito cilindros de cada amostra a fim de se obter maior precisão nos dados. O aparelho utilizado na análise foi um Warner-Bratzler Shear Force mecânico com capacidade de $25 \mathrm{~kg}$ e velocidade do seccionador de 20 $\mathrm{cm} /$ minuto. Após sete dias, as amostras que foram submetidas a maturação passaram pelo mesmo procedimento descrito acima.
Das amostras não maturadas $\mathrm{e}$ maturadas por sete dias, foram também retirados pedaços para a determinação da composição proteica do músculo Longissimus e análise das alterações nas frações das proteínas miofibrilares por SDS-Page.

As amostras, resfriadas por 24 horas e maturadas por sete dias, utilizadas nestas análises foram embaladas em papel alumínio e congeladas a $-80^{\circ} \mathrm{C}$ até a data da realização das análises, para evitar degradação indesejável das proteínas miofibrilares, que ocorre sob refrigeração.

Para o isolamento das miofibrilas, foi adotado o protocolo descrito por Clayes et al. (1995) com algumas adaptações descritas a seguir. Aproximadamente $1 \mathrm{~g}$ de amostra do músculo Longissimus, livre de gordura e tecido conjuntivo foi homogeneizada em $10 \mathrm{~mL}$ de tampão de lise $(50 \mathrm{mM}$ de Tris- $\mathrm{HCl}, 0,25 \mathrm{M}$ de sacarose, $1 \mathrm{mM}$ de EDTA) usando um microtriturador Ultra-Turrax com haste de cisalhamento (Marconi - MA 102/E).

Após a homogeneização, as amostras foram centrifugadas a $1000 \mathrm{xg}$ por 10 minutos a $4^{\circ} \mathrm{C}$. O sobrenadante foi descartado, o precipitado(pellet) ressuspendido em $10 \mathrm{~mL}$ de nova solução de isolamento $(50 \mathrm{mM}$ de TRIS-HCl, 1 $\mathrm{mM}$ de EDTA) e levado novamente a centrifuga a $1000 \mathrm{x} g$ por 10 minutos a $4^{\circ} \mathrm{C}$.

A seguir, o sobrenadante foi novamente descartado; as miofibrilas foram ressuspendidas em $10 \mathrm{~mL}$ de solução de $\mathrm{KCl}(0,15 \mathrm{mM})$, levando-se os tubos novamente a centrifuga por 10 minutos a $1000 \mathrm{x} g$ e $4^{\circ} \mathrm{C}$.

Após descartar o sobrenadante, as miofibrilas isoladas $(0,9 \mathrm{~g})$ foram dissolvidas em $12 \mathrm{~mL}$ de uma quarta solução (10 mM de Imidazol-HCL, 2\% de dodecil sulfato de sódio (SDS) e $2 \%$ de $\beta$-mercaptoetanol). Após isto, os 
tubos contendo as miofibrilas dissolvidas foram tampados e deixados durante 24 horas sob refrigeração.

O precipitado formado foi, então, ressuspendido. Cada uma das amostras foi filtrada em lã de vidro siliconizada e o conteúdo de cada tubo $(12 \mathrm{~mL})$ foi, ao final do procedimento aliquotado em um tubo de $10 \mathrm{~mL}$ para realização da quantificação pelo método de Microkjeldahl e em 2 tubos de $1 \mathrm{~mL}$ cada para serem usados na corrida eletroforética. Os três tubos devidamente identificados foram congelados a $-20^{\circ} \mathrm{C}$ até sua utilização para evitar degradação indesejada das miofibrilas.

Para a quantificação de nitrogênio total foi utilizado o método de Micro-Kjedahl, seguindo procedimento adotado por Clayes (1995). Este método foi escolhido, pois o SDS e o $\beta$-mercaptoetanol presentes nas amostras interferem nos resultados de quantificação por outros métodos, como o do Macro-Biureto.

Foram utilizados $5 \mathrm{~mL}$ de solução de cada amostra das miofibrilas previamente isoladas em tubo de digestão, devidamente numerados em duas repetições, contendo $0,8 \mathrm{~g}$ de mistura digestora $\left(1 \mathrm{~g}\right.$ de $\mathrm{Na}_{2} \mathrm{SEO}_{3} ; 5 \mathrm{~g}$ $\mathrm{CuSO}_{4} ; 76,71 \mathrm{~g}$ de $\mathrm{Na} \mathrm{SO}_{4}$ triturados em graal de porcelana) e $4,0 \mathrm{~mL}$ de $\mathrm{H}_{2} \mathrm{SO}_{4}$ concentrado. Os tubos permaneceram durante a noite sob refrigeração para a digestão a frio e posteriormente foram colocados em bloco digestor até atingirem a temperatura de $400{ }^{\circ} \mathrm{C}$ (digestão a quente).

Procedida a digestão foram adicionados aos tubos $10 \mathrm{~mL}$ de água destilada e 10 $\mathrm{mL}$ de ácido bórico com indicador $(20 \mathrm{~g}$ de ácido bórico, $800 \mathrm{~mL}$ de água destilada, $6,0 \mathrm{~mL}$ de solução alcoólica de vermelho de metila $0,1 \%$ e $15 \mathrm{~mL}$ de solução alcoólica de verde de bromofenol $0,1 \%$, completados com água destilada para $1000 \mathrm{~mL}$ ) e realizou-se, então, a destilação da amostra com aproximadamente $10 \mathrm{~mL}$ de $\mathrm{NaOH} 15 \mathrm{~N}$, recolhendo-se ao final aproximadamente $30 \mathrm{~mL}$ do destilado.

Após a destilação as amostras permaneceram sob refrigeração e em seguida foram tituladas com $\mathrm{H}_{2} \mathrm{SO}_{4} 0,05 \mathrm{~N}$ padronizado (fator 0,04494 ). Procedida à titulação, foram realizados os cálculos das concentrações de proteína da seguinte forma:

mg de proteína $/ \mathrm{mL}=$

$$
\frac{(V A C-B R) \times N \times 14 \times 6,25}{V A M} \text { onde: }
$$

$\mathrm{VAC}=$ Volume do ácido sulfúrico concentrado

$\mathrm{BR}=$ Valor do Branco

$\mathrm{N}=$ Fator do ácido sulfúrico

$\mathrm{VAM}=$ volume da amostra

Após o isolamento e quantificação das miofibrilas, procedeu-se a eletroforese na presença de dodecil sulfato de sódio (SDS-PAGE) para verificação da proteólise miofibrilar das frações separadas das proteínas.

Foram empregados no presente estudo géis de poliacrilamida compostos de duas partes, o gel concentrador ou empilhador a $4 \%$ de concentração - 10 $\mathrm{mL}$ água Milli-Q, $3 \mathrm{~mL}$ de Tris $(1,5 \mathrm{mM}$ $\mathrm{pH}$ 6,8), $3 \mathrm{~mL}$ de acrilamida/Bis $(30: 0,8)$ e $2,5 \mathrm{~mL}$ de riboflavina e gel fracionador ou separador a $10 \%$ - 16,4 mL de Água

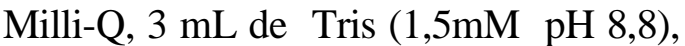
$10 \mathrm{~mL}$ de acrilamida/Bis (30:0,8), 200 $\mu \mathrm{L}$ de Persulfato de Amônio a 10\%, 200 $\mu \mathrm{L}$ de SDS a $10 \%$ e $60 \mu \mathrm{L}$ de temed.

Para composição dos moldes dos géis utilizados na eletroforese, duas placas de vidro de $14 \mathrm{~cm}$ x $16 \mathrm{~cm}$ x $0,10 \mathrm{~cm}$ foram justapostas, separadas por espaçadores laterais. Este conjunto foi então embalado em saco plástico e mantido por presilhas para conter os géis.

Terminada a montagem dos moldes, procedeu-se à preparação e aplicação dos géis na placa da seguinte forma: o 
gel separador foi aplicado até uma altura suficiente para o encaixe do pente e aplicação do gel empilhador. Após isso, aplicou-se aproximadamente $3 \mathrm{~mL}$ de água destilada para evitar contato do gel com o oxigênio, evitando irregularidades na superfície do gel e a formação de bolhas. Após a polimerização do gel separador o pente foi colocado no topo dos moldes e em seguida, aplicou-se o gel empilhador. Completada a polimerização deste gel sob luz ultravioleta, o pente foi retirado e procedeu-se a lavagem dos poços formados com água deionizada. Após isso foi aplicado o tampão eletrodo, para posterior corrida eletroforética.

As proteínas solubilizadas foram padronizadas em 4,0 $\mathrm{mg}$ de proteína/mL de solução e receberam uma solução carregadora preparada pela adição de sacarose a $15 \%$ (para aumentar a densidade da solução) e $0,3 \mathrm{~mL}$ de azul de bromofenol (como marcador de migração para SDS-PAGE). Após esta preparação cada amostra foi aplicada nos poços do gel. Para a identificação do peso molecular das proteínas de interesse, foi adicionado no primeiro poço do gel um padrão de peso molecular (Kaleidoscope, Biorad).

A eletroforese processou-se de acordo com os seguintes parâmetros: $100 \mathrm{~V}, 10$ $\mathrm{mA}$ e $10 \mathrm{~W}$, durante aproximadamente 6 horas. Após a eletroforese o gel foi colocado em solução corante (Comassie blue - R250 em solução de ácido acético conforme instruções do fabricante) por aproximadamente 3 horas. A seguir, o corante foi retirado e o gel foi imerso em solução descorante (água/metanol/ácido acético 1:3:6, V/V) até a completa revelação das bandas proteicas no gel.

A captação das imagens das bandas foi realizada por meio de um equipamento de foto-documentação (VDS) para se identificar as mudanças na estrutura das proteínas miofibrilares. Os géis foram analisados utilizando o programa para análise de imagens Image Máster $3 D$ Prime \& Elite.

Para análise das bandas, os géis foram digitalizados empregando-se o Software Image Máster, sendo as imagens editadas pelo Software Adobe Photopoint 5.0. Na eletroforese foram analisadas as mobilidades relativas de acordo com os pesos moleculares, que identificam as frações separadas.

Os valores da contribuição relativa de cada banda no gel, obtidos das análises das imagens, foram submetidos, posteriormente, a análises estatísticas para verificação da significância das mudanças.

Os resultados obtidos para a força de cisalhamento e mudanças nos padrões das proteínas miofibrilares foram analisados por meio do procedimento GLM do pacote estatístico SAS (SAS Intitute, 1990). O delineamento experimental utilizado para as análises foi o inteiramente ao acaso em esquema fatorial $2 \times 4$, considerando-se nas análises os efeitos da maturação por 7 dias ou não maturação e quatro grupos genéticos (Nelore; cruzados $1 / 2$ Nelore $1 / 2$ Aberdeen-Angus x Brahman; Brangus e cruzados $1 / 2$ nelore $1 / 2$ Aberdeen-Angus $x$ Pardo). Foi realizada a análise de variância para as características estudadas e as médias foram comparadas pelo teste de Tukey à 5\% de probabilidade.

\section{RESULTADOS E DISCUSSÃO}

A Tabela 1 mostra os valores médios da força de cisalhamento dos cortes dos animais dos quatro grupos genéticos, não maturados (resfriadas por 24 horas) ou submetidos a sete dias de maturação. Não foram encontradas diferenças significativas na maciez da carne, 
medida pela análise da força de cisalhamento $(\mathrm{p}>0,05)$.A falta de diferença na textura da carne dos diferentes grupos deste estudo pode ser explicada, provavelmente, pela baixa idade em que esses animais foram abatidos, assim como verificado por Bianchini et al. (2007) trabalhando com animais Nelore, Simental, Simbrasil e $1 / 2$ Simental $\mathrm{x}$ Nelore confinados sob modelo biológico superprecoce. Por causa do sistema de terminação em que foram criados, mesmo animais de grupos genéticos extremos, apresentaram características de carcaça bastante semelhantes. Este fato pode ser atribuído às poucas variações encontradas na curva de crescimento corporal dos animais quando abatidos ainda jovens (BIANCHINI et al., 2008).

Tabela 1. Valores médios da força de cisalhamento do músculo Longissimus não maturado ou maturado por 7 dias

\begin{tabular}{lcc}
\hline \multirow{2}{*}{ Grupo genético } & \multicolumn{2}{c}{ Força de cisalhamento $(\mathrm{kg})$} \\
\cline { 2 - 3 } & $\begin{array}{c}\text { Não } \\
\text { maturado }\end{array}$ & $\begin{array}{c}\text { Maturado por } \\
7 \text { dias }\end{array}$ \\
\hline Nelore & $3,54^{\mathrm{aA}}$ & $3,50^{\mathrm{aA}}$ \\
TRC-Brahman & $3,77^{\mathrm{aA}}$ & $3,75^{\mathrm{aA}}$ \\
Brangus & $3,20^{\mathrm{aA}}$ & $3,15^{\mathrm{aA}}$ \\
TRC-Pardo & $3,55^{\mathrm{aA}}$ & $3,50^{\mathrm{aA}}$ \\
\hline
\end{tabular}

Médias seguidas por letras maiúsculas iguais na mesma linha não diferem quanto ao tempo de maturação e letras minúsculas iguais na mesma coluna não diferem entre si quanto ao grupo genético pelo teste Tukey $(\mathrm{p}<0,05)$.

Legendas: TRC - Brahman: cruzados $1 / 2$ Nelore $1 / 2$ Aberdeen-Angus x Brahman; TRC - Pardo: cruzados $1 / 2$ nelore $1 / 2$ Aberdeen-Angus x Pardo

Tanto as amostras refrigeradas por 24 horas quanto as que sofreram maturação por 7 dias apresentaram resultados de maciez satisfatória, medidos pela força de cisalhamento. Vaz et al. (2007) demonstraram que abate de animais em idade jovem e períodos de alimentação curtos não influenciam na textura da carne.Tais observações demonstram a importância da adoção de tecnologias que possibilitem a diminuição da idade dos animais ao abate para melhora na maciez da carne desses animais, já que o menor tempo de estocagem da carne resulta em retorno mais rápido para a indústria da carne, além de economia de energia e espaço físico para o armazenamento, possibilitando assim maior circulação dos produtos.

A Figura 1 mostra a porcentagem relativa de cada banda no gel de eletroforese.São apresentadas oito linhas representativas do padrão eletroforético das proteínas miofibrilares do músculo Longissimus dos quatro grupos genéticos estudados, após 24 horas de resfriamento e 7 dias de maturação. Esta mostrou de 22 a 27 bandas.

Os valores do conteúdo das proteínas miofibrilares do músculo Longissimus dos diferentes grupos genéticos estudados que não foram maturados e os maturados por 7 dias são mostrados na Tabela 2.

Verificou-se no presente estudo, diferenças no conteúdo da miosina $(\mathrm{p}<$ $0,05)$. O mesmo relatado por Sawdy et al. (2004), também em estudo com animais jovens, confirmando os resultados obtidos na eletroforese, com análises de "immunoblot" e espectrometria de massas. As diferenças na cadeia pesada da miosina podem ter ocorrido enquanto a carcaça não estava sob refrigeração, situação que favorece a atividade de outras enzimas, além das calpaínas, relatadas neste estudo, como por exemplo, o sistema das catepsinas, que degradam miosina e actina.

Diferenças quanto ao conteúdo da miosina foram observadas com relação ao grupo $1 / 2$ Nelore $1 / 2$ Aberdeen-Angus $\mathrm{x}$ Pardo. Este grupo apresentou menor conteúdo de miosina em relação aos 
outros grupos de maior percentagem de zebu em sua constituição. Isto pode estar relacionado a diferenças no conteúdo proteico e atividade das enzimas proteolíticas deste grupo genético, além da composição do músculo Longissimus desses animais e de diferenças de isoformas de miosina.

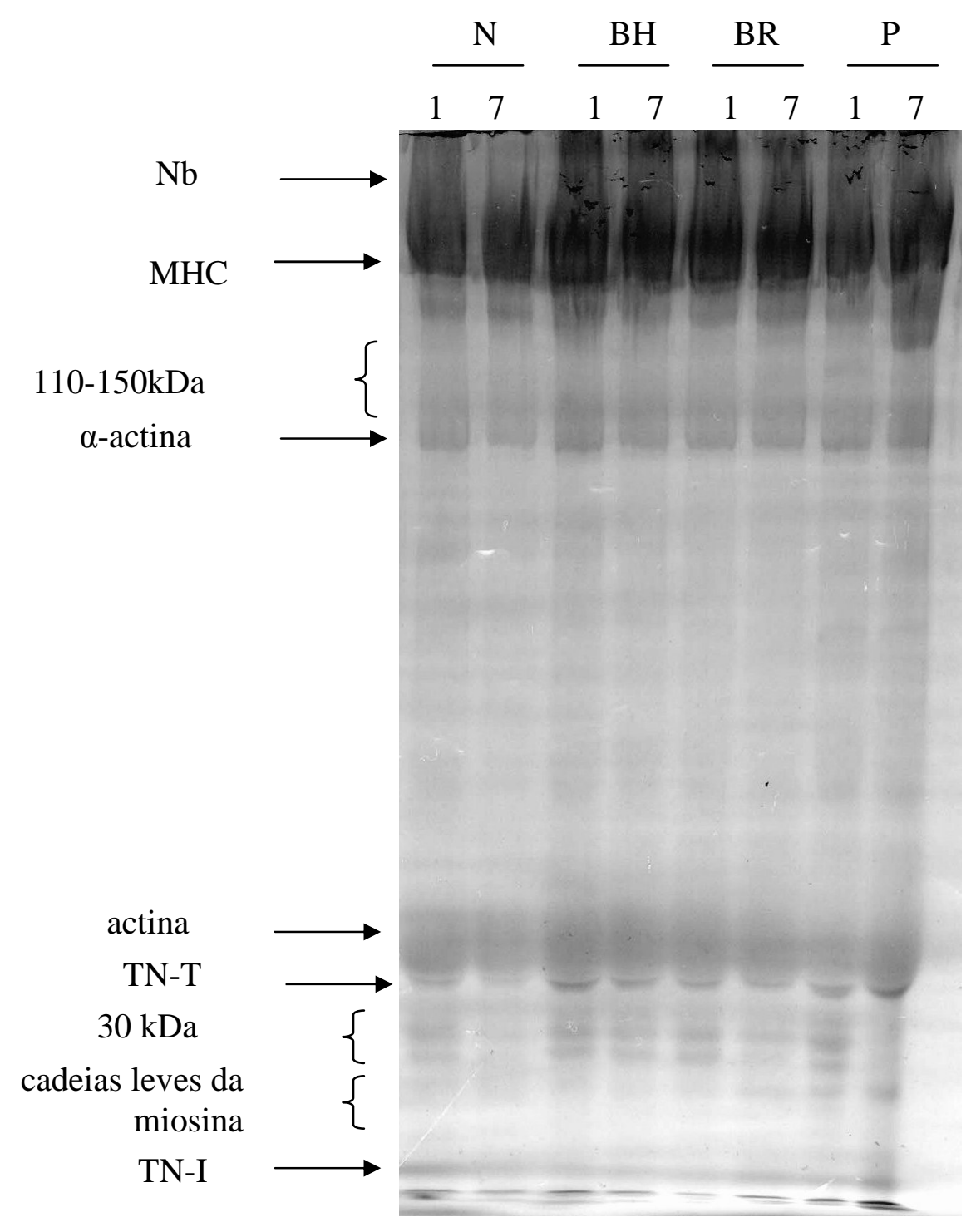

Legendas: N - Nelore, BH - cruzados 1/2 Nelore $1 / 2$ Aberdeen-Angus x Brahman; BR - Brangus, P- cruzados $1 / 2$ nelore $1 / 2$ Aberdeen-Angus x Pardo. 1 - amostra não maturada; 7 - amostra maturada por 7 dias.Nb - nebulina; MHC - cadeia pesada da miosina; 110-150kDa - fragmentos da MHC; TN-T - troponina T; 30kDa fragmentos da degradação da troponina-T; TN-I - troponina I.

Figura 1. Eletroforese em SDS-PAGE (10\%) das proteínas miofibrilares do músculo Longissimusde bovinos de quatro grupos genéticos resfriadas por 24 horas ou maturadas por sete dias 
Rev. Bras. Saúde Prod. Anim., Salvador, v.15, n.4, p.1027-1037 out./dez., 2014 http://www.rbspa.ufba.br ISSN 15199940

Tabela 2. Mudanças no conteúdo das proteínas miofibrilares do músculo Longissimusde bovinos Nelore, TRC-Brahman, Brangus e Pardo, não maturadas ou maturadas por 7 dias

\begin{tabular}{|c|c|c|c|c|}
\hline Proteínas & Grupos Genéticos & $1 \mathrm{dia}$ & 7 dias & Médias \\
\hline \multirow[t]{5}{*}{$\mathrm{MHC}$} & Nelore & 47,05 & 41,73 & $44,40^{\mathrm{A}}$ \\
\hline & TRC-Brahman & 49,17 & 37,95 & $43,56^{\mathrm{AB}}$ \\
\hline & Brangus & 48,75 & 43,67 & $46,21^{\mathrm{A}}$ \\
\hline & TRC-Pardo & 40,15 & 35,33 & $37,74^{\mathrm{B}}$ \\
\hline & Médias & $46,29^{\mathrm{a}}$ & $39,67^{\mathrm{b}}$ & \\
\hline \multirow[t]{5}{*}{$\alpha$ - actina } & Nelore & 4,88 & 5,54 & $5,21^{\mathrm{A}}$ \\
\hline & TRC-Brahman & 5,98 & 6,12 & $6,05^{\mathrm{A}}$ \\
\hline & Brangus & 5,58 & 5,94 & $5,76^{\mathrm{A}}$ \\
\hline & TRC-Pardo & 5,22 & 5,58 & $5,40^{\mathrm{A}}$ \\
\hline & Médias & $5,42^{\mathrm{a}}$ & $5,80^{\mathrm{a}}$ & \\
\hline \multirow[t]{5}{*}{ Actina } & Nelore & 10,39 & 10,23 & $10,32^{\mathrm{A}}$ \\
\hline & TRC-Brahman & 11,79 & 10,57 & $11,18^{\mathrm{A}}$ \\
\hline & Brangus & 9,87 & 10,82 & $10,35^{\mathrm{A}}$ \\
\hline & TRC-Pardo & 11,23 & 11,68 & $11,46^{\mathrm{A}}$ \\
\hline & Médias & $10,82^{\mathrm{a}}$ & $10,83^{\mathrm{a}}$ & \\
\hline \multirow[t]{5}{*}{ TNT-T } & Nelore & 2,57 & 2,09 & $2,33^{\mathrm{A}}$ \\
\hline & TRC-Brahman & 3,07 & 2,35 & $2,71^{\mathrm{A}}$ \\
\hline & Brangus & 3,11 & 2,63 & $2,87^{\mathrm{A}}$ \\
\hline & TRC-Pardo & 3,13 & 2,53 & $2,83^{\mathrm{A}}$ \\
\hline & Médias & $2,97^{\mathrm{a}}$ & $2,40^{\mathrm{a}}$ & \\
\hline \multirow[t]{5}{*}{$30 \mathrm{kDa}$} & Nelore & 0,19 & 0,74 & $0,47^{\mathrm{A}}$ \\
\hline & TRC-Brahman & 0,68 & 1,26 & $0,97^{\mathrm{A}}$ \\
\hline & Brangus & 0,85 & 1,03 & $0,95^{\mathrm{A}}$ \\
\hline & TRC-Pardo & 0,87 & 1,23 & $1,05^{\mathrm{A}}$ \\
\hline & Médias & $0,65^{\mathrm{a}}$ & $1,07^{\mathrm{b}}$ & \\
\hline \multirow[t]{5}{*}{ TN-I } & Nelore & 4,88 & 5,54 & $5,21^{\mathrm{A}}$ \\
\hline & TRC-Brahman & 5,98 & 6,12 & $6,05^{\mathrm{A}}$ \\
\hline & Brangus & 5,58 & 5,94 & $5,76^{\mathrm{A}}$ \\
\hline & TRC-Pardo & 5,22 & 5,57 & $5,40^{\mathrm{A}}$ \\
\hline & Médias & $5,41^{\mathrm{a}}$ & $5,80^{\mathrm{a}}$ & - \\
\hline
\end{tabular}

Médias seguidas por letras maiúsculas iguais na mesma coluna não diferem significativamente quanto aos grupos genéticos e letras minúsculas iguais na mesma linha não diferem significativamente quanto aos tempos de maturação pelo teste Tukey $(\mathrm{P}>0.05)$.

Legendas: TRC $=$ Brahman: cruzados $1 / 2$ Nelore $1 / 2$ Aberdeen-Angus $\times$ Brahman; TRC $=-$ Pardo: cruzados $1 / 2$ nelore $1 / 2$ Aberdeen-Angus x Pardo

Não foi observada qualquer mudança no conteúdo da $\alpha$-actina $(\mathrm{p}>0,05)$ após a maturação. Tal observação pode ser explicada, pois pouca ou nenhuma degradação desta proteína é verificada durante a estocagem postmortem. As catepsinas degradam a actina e miosina, além da estrutura dos discos $\mathrm{Z}$ a $37^{\circ} \mathrm{C}$ e liberam a $\alpha$-actina intacta (TAYLOR et al., 1995).

A actina não foi degradada durante o período postmortem. Sawdy et al. (2004) relacionando a contribuição relativa de diferentes bandas da eletroforese com a maciez obtida pela força de cisalhamento, retiraram a contribuição da banda referente à actina do modelo de regressão. 
Como esta proteína parece não sofrer qualquer mudança e por sua alta densidade ótica, sua retirada pode auxiliar na identificação de outras bandas menores que podem influenciar significativamente a maciez da carne.

Não foram encontradas diferenças significativas quanto ao conteúdo da Troponina-T durante o período de maturação em nenhum dos grupos genéticos $(p>0,05)$. Apesar disto, verificase com a maturação, que o conteúdo da Troponina-T teve leve diminuição e devido à degradação desta proteína, polipeptídeos de aproximadamente 30 kDa aparecem (MARINO et al., 2013).

Mesmo nas amostras que não foram maturadas por sete dias o fragmento de $30 \mathrm{kDa}$ apareceu, e se intensificou com o período de maturação em todos os grupos genéticos. Pequenos fragmentos derivados da Troponina- $T$ foram relatados por Marino et al. (2013), quando estudou o efeito da raça e tempo de maturação sobre proteólise miofibrilar, utilizando eletroforese SDS -PAGE e bidimensional com bovinos jovens cruzados Romagnola $\mathrm{x}$ Podolian $\mathrm{e}$ Podolian x Friesan.

No presente estudo, menor aparecimento antes da maturação foi verificado para os animais Nelore. Porém, após 7 dias a deposição deste fragmento se assemelhou à dos outros grupos. A degradação da Troponina-T durante a maturação dos músculos tem sido associada com o aumento da maciez da carne ao longo do tempo (IWANOWSKA et al., 2010).

Devido à falta de diferenças na maciez medida pela análise da força de cisalhamento dos quatro grupos genéticos estudados ( $>00,05)$, não houve possibilidade de se associar algum efeito das diferenças da proteólise observada na eletroforese com maciez da carne no presente estudo.
A análise densitométrica das bandas das cadeias leves da miosina foi problemática, devido à proximidade dessas duas cadeias e do grande número de bandas que apareceram nesta região após a maturação (produtos da proteólise durante a maturação).

Apesar de visível em todos os géis deste estudo, a banda da Troponina-I alcançou níveis muito altos em alguns géis, o que pode ser explicado por sua proximidade com o final do gel. Desta forma, ela se confunde na análise densitométrica com a frente de corrida, o que pode ter atrapalhado sua correta quantificação.

Como a abordagem aqui adotada para se medir a proteólise considera apenas os pesos moleculares das proteínas ou polipeptídeos de interesse, pode ter ocorrido numa mesma banda a presença de diferentes frações proteicas com $o$ mesmo peso molecular (comigração), principalmente das proteínas de menor peso. Assim, com a intensificação no aparecimento dos produtos de degradação, à medida que se aumenta o tempo de maturação e consequentemente a degradação miofibrilar, pode-se estar subestimando a taxa de degradação total aos sete dias de maturação.

Uma alternativa seria a complementação da eletroforese com o uso da Isoeletrofocalização (IEF) ou mesmo a eletroforese bidimensional. Assim, além da separação das proteínas por peso molecular, teremos também sua separação por pontos isoelétricos, o que pode proporcionar maior compreensão das mudanças estruturais e da taxa de proteólise com o aumento do tempo de maturação.

Tanto o período de 24 horas de resfriamento, quanto o período de sete dias de maturação resultaram em carne com maciez aceitável, não sendo observadas diferenças para esta característica entre os grupos genéticos estudados. 
Mudanças ocorrem no conteúdo da cadeia pesada da miosina durante a maturação. $\mathrm{O}$ mesmo ocorre com a Troponina-T das proteínas miofibrilares, estando sua proteólise relacionada com o aumento dos produtos de degradação ao redor de $30 \mathrm{kDa}$.

No presente estudo a maturação não tem efeito importante nas mudanças das proteínas miofibrilares. A maturação leva ao surgimento de várias frações de proteínas no gel de eletroforese relacionadas à maciez, contudo, no presente estudo não houve diferenças na maciez que possam ser explicadas pelas mudanças nas proteínas miofibrilares. A pouca idade dos animais ao abate determina boa maciez da carne, independentemente do grupo genético ou tempo de maturação.

\section{REFERÊNCIAS}

BIANCHINI, W.; SILVEIRA, A.C.; JORGE, A.M.; ARRIGONI, M.B.; MARTINS, C.L.; RODRIGUES, E.; HADLICH, J.C.; ANDRIGHETO, C. Efeito do grupo genético sobre as características de carcaça e maciez da carne fresca e maturada de bovinos superprecoces. Revista Brasileira de Zootecnia, v.36, p.2019-2117, 2007.

BIANCHINI, W.; SILVEIRA, A.C.; ARRIGONI, M.B.; MENDES, A.M.; MARTINS, C.L.; RODRIGUES, E. Crescimento e características de carcaça de bovinos superprecoces Nelore, Simental e mestiços. Revista Brasileira de Saúde e Produção Animal [online], v.9, n.3, p.554-564, 2008.

BRASIL. Ministério da Agricultura, Pecuária e Abastecimento. Instrução normativa n. 3, de 17de janeiro de 2000. Aprova o regulamento técnico de métodos de insensibilização para o abate humanitário de animais de açougue. Diário Oficial da União, Brasília, 24 jan. 2000. Seção 1, p.14.

\section{CLAYES, E.; UYTTERHAEGEN,} BUTS, B.; DEMEYER, D.

Quantification of beef myofibrillar proteins by SDS-PAGE. Meat Science, v.39, p.177, 1995.

IWANOWSKA, A.; IWANSKA, E.; GRZÉS, B.; MIKOŁAJCZAK, B.; POSPIECH, E.; ROSOCHACKI, S.; JUSZCZUK-KUBIAK, E.; ŁYCZYNSSKI, A. Changes in proteins and tenderness of meat from young bulls of four breeds at three ages over 10 days of cold storage. Animal

Science Papers and Reports, v.28, p.13-25, 2010.

KOOHMARAIE, M, GEESINK, G.H. Contribution of post-mortem biochemistry to the delivery of consistent meat quality with particular focus on the calpain system. Meat Science, v.74, p.34-43, 2006.

HUFF LONERGAN, E.; ZHANG, W.; LONERGAN, S.M. Biochemistry of postmortem muscle: lessons on mechanisms of meat tenderization. Meat Science, v.86, p.184-195, 2010.

MARINO, R.; ALBENZIO, M.; MALVA, A.D.; SANTILLO, A.; LOIZZO, P.; SEVI, A. Proteolytic pattern of myofibrillar protein and meat tenderness as affected by breed and aging time. Meat Science, v.95, p.281287, 2013.

MÓNSON, F.C.; SAÑUDO, C.; SIERRA, I. Influence of cattle breed and ageing time on textural met quality. Influence of cattle breed and ageing time on textural meat quality. Meat Science, v.68, p.595-602, 2004. 
PIGHIN, D. G. Electrophoresis as a useful tool in studying the quality of meat products. In: GHOWSI, K.

Electrophoresis. Rijeka: InTech, 2012. p.117-136.

SAÑUDO, C.; MACIE, E.S.; OLLETA, J.L.; VILLARROEL, M.; PANEA, B.; ALBERTI, P. Meat Science, v.66, p.925-932, 2004.

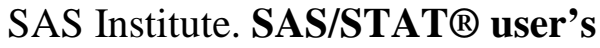
guide. Version 6. 4.ed. Cary, NC, 1990

SAWDY, J.C.; KAISER, S.A.; ST.PIERRE, N.R.; WICK, M.P. Myofibrillar 1-D fingerprints and myosin heavy chain MS analyses of beef loin at $36 \mathrm{~h}$ postmortem correlate with tenderness at 7 days. Meat

Science, v.67, p.421-426, 2004.

TAYLOR, R.G.; GEESINK, G.H.; THOMPSON, V.F.; KOOHMARAIE, M.; GOLL, D.E. Is Z-Disk degradation responsible for post-mortem tenderization? Journal of Animal Science, v.73, p.1351-1367, 1995.
VAZ, F.N.; RESTLE, J.; PADUA, J.T. Qualidade da carcaça e da carne de novilhos abatidos com pesos similares, terminados em diferentes sistemas de alimentação. Ciência Animal

Brasileira, v.8, n.1, p.31-40, 2007.

VIEIRA, C.; GARCIA CACHÁN, M. D.; RECIO, M.D.; DOMINGUEZ, M.; SAÑUDO, C. Effect of ageing time on beef quality of rustic type and rustic $\mathrm{X}$ Charolais crossbreed cattle slaughtered at the same finishing grade. Spanish

Journal of Agricultural Research, v.4, n.3, p.225-234, 2006.

WHEELER, T.L.; SHACKELFORD, S.D.; KOOHMARAIE, M.

Standardizing collection and interpretation of Warner-Bratzler shear force and sensory tenderness data. In: Proceedings of the Reciprocal Meat Conference, v.50, p.68-77, 1997.

Data de recebimento: 16/08/2014 Data de aprovação: 17/11/2014 